\title{
Interactive comment on "Hydrodynamic simulation of the effects of in-channel large woody debris on the flood hydrographs of a low mountain range creek, Ore Mountains, Germany" by Daniel Rasche et al.
}

Daniel Rasche et al.

christian.reinhardt-imjela@fu-berlin.de

Received and published: 18 April 2019

The comment was uploaded in the form of a supplement:

https://www.hydrol-earth-syst-sci-discuss.net/hess-2019-35/hess-2019-35-AC1-

supplement.pdf 